\title{
Hop tests and psychological PROs provide a demanding and clinician-friendly RTS assessment of patients after ACL reconstruction, a registry study.
}

\section{Ramana Piussi}

Sportrehab, Sports rehabilitation clinic https://orcid.org/0000-0001-7586-5293

\section{Susanne Beischer}

Goteborgs universitet Institutionen for neurovetenskap och fysiologi

Roland Thomeé

Goteborgs universitet Institutionen for neurovetenskap och fysiologi

Eric Hamrin Senorski ( $\square$ eric.hamrin.senorski@gu.se )

https://orcid.org/0000-0002-9340-0147

\section{Research article}

Keywords: Knee; Evaluation; Test batteries; Anterior Cruciate Ligament

Posted Date: March 5th, 2020

DOI: https://doi.org/10.21203/rs.3.rs-16194/v1

License: (c) (1) This work is licensed under a Creative Commons Attribution 4.0 International License. Read Full License

Version of Record: A version of this preprint was published at BMC Sports Science, Medicine and Rehabilitation on May 13th, 2020. See the published version at https://doi.org/10.1186/s13102-02000182-z. 


\section{Abstract}

Background There is growing interest in assessing psychological well-being in patients after anterior cruciate ligament $(\mathrm{ACL})$ reconstruction. It is unknown whether an assessment of psychological outcome in addition to tests of muscle function can facilitate decisions on return to sport. Therefore, the aim was to evaluate different return to sport (RTS) test batteries, comprising both muscle function and psychological outcomes 1 year after ACL. Method In this cross-sectional cohort study a total of 320 patients (51\% men) aged 18-65 years were included 1 year after ACL reconstruction. Different muscle function (MF) test batteries consisting of knee extension and flexion strength tests, 3 hop tests, and 2 psychological patient-reported outcomes (PROs); Quality of Life subscale from the Knee injury and Osteoarthritis Outcome Score (KOOS QoL) and ACL Return to Sport after Injury (ACL-RSI), 1 year after ACL reconstruction. Results Passing rates in the different test batteries varied from $47 \%$ for 2 hop tests to $13 \%$ for $5 \mathrm{MF}$ tests +2 PROs. The use of psychological PROs together with tests of muscle function gave the lowest passing rates. There was a very strong correlation between passing 2 hop tests +2 PROs and passing $5 \mathrm{MF}$ tests as well as passing $5 \mathrm{MF}$ tests $+2 \mathrm{PROs}$. Conclusion The use of hop tests together with psychological PROs provides a demanding and clinician-friendly RTS test battery for assessment 1 year after $A C L$ reconstruction.

\section{Introduction}

Much attention is paid to a safe return to sport (RTS) after an anterior cruciate ligament (ACL) injury, as a safe RTS is a milestone for a majority of patients.[1, 2] Reaching RTS criteria based on an objective assessment of muscle function (MF) in the lower extremity, prior returning to sport, can reduce the risk of a second ACL injury. $[3,4]$ A proper assessment of MF after ACL injury and reconstruction should comprise measures of quadriceps and hamstring strength as well as measures of functional performance.[5] As an athletic injury always is followed by a psychological response, psychological outcome measures have become more common in the assessment of patients with an ACL injury.[6, 7] Results from, for example, only hop performance can thus be insufficient as RTS criteria. Furthermore, it has been reported that as demands increase by adding more muscle function tests, the passing rate (the proportion of patients reaching a given cut-off value) is reduced.[8-10] It is, however, unknown if adding an assessment of psychological outcome to MF tests will give a better base for decisions on RTS.

The aim of this study was to evaluate different RTS test batteries, comprising both MF and psychological patient-reported outcomes 1 year after ACL reconstruction.

\section{Methods}

This cross-sectional study was based on data extracted from a rehabilitation outcome registry, Project ACL, on 8 February 2019. Project ACL was established in 2014 and aims both to improve the care of patients with an ACL injury through the use of regular assessments as well as to provide patients and clinicians with treatment feedback in Project ACL. Data are collected prospectively at predefined follow- 
ups with ACL injury or ACL reconstruction as baseline.[11-13] The follow-up data consist of validated tests of MF and patient-reported outcomes (PROs). The patients undergo individualized rehabilitation under supervision of a registered physical therapist. Ethical approval has been obtained from the Regional Ethical Review Board (registration numbers: 265 - 13, T023-17).

In the present study, data from the 1-year follow-up were extracted for analysis. Patients included in the registry were eligible if: aged 18-65 years; had undergone a unilateral ACL reconstruction and attended Project ACL's 1-year follow-up. Patients were excluded if any of the following criteria was met; registered with a second ACL injury, had not performed one of the five tests in the battery of MF tests, or had not responded to the Knee injury and Osteoarthritis Outcome Score, subscale Quality of Life (KOOS QoL) or the ACL Return to Sport after Injury scale (ACL-RSI).

\section{Muscle function}

The tests of MF comprised of 2 strength and 3 hop tests. Patients are required to go through a detailed familiarization procedure with their responsible physical therapist before they are tested in Project ACL. Before testing, patients performed a standardized warm up of 10 minutes on a stationary bike and sub maximum trials on each test (Table 1).[14]

\section{Table 1. Tests of muscle function.}

\begin{tabular}{|c|c|c|c|c|c|}
\hline & $\begin{array}{l}\text { Degrees of } \\
\text { movement }\end{array}$ & $\begin{array}{l}\text { Practice } \\
\text { trials } \\
n(\% \text { of } \\
1 \mathrm{RM})\end{array}$ & $\begin{array}{l}\text { Test } \\
\text { trials } \\
\text { (n) }\end{array}$ & $\begin{array}{l}\text { Rest between test trials } \\
\text { (seconds) }\end{array}$ & Units \\
\hline $\begin{array}{l}\text { Knee } \\
\text { extension }\end{array}$ & $90^{\circ}-0^{\circ}$ & $\begin{array}{l}10(50 \%) \\
10(75 \%) \\
1-2 \\
(90 \%)\end{array}$ & $3-4$ & 40 & $\begin{array}{l}\text { Newton } \\
\text { meters }\end{array}$ \\
\hline Knee flexion & $0^{\circ}-90^{\circ}$ & $\begin{array}{l}10(50 \%) \\
10(75 \%) \\
1-2 \\
(90 \%)\end{array}$ & $3-4$ & 40 & $\begin{array}{l}\text { Newton } \\
\text { meters }\end{array}$ \\
\hline Vertical hop & - & 2 & 3 & 20 & Centimeters \\
\hline $\begin{array}{l}\text { Hop for } \\
\text { distance }\end{array}$ & - & 2 & $3-5$ & 20 & Centimeters \\
\hline Side hop & - & - & $\begin{array}{l}30 \\
\text { seconds }\end{array}$ & 180 & $\begin{array}{l}\text { Number of } \\
\text { hops }\end{array}$ \\
\hline
\end{tabular}


Maximum concentric knee muscle strength was tested in unilateral knee extension and knee flexion at $90 \%$ second on an isokinetic dynamometer (Biodex System 4; Biodex Medical System, Shirley, NY, USA). The Biodex dynamometer is reliable for testing muscle strength.[15] Peak torque in Newton meters (Nm) was used for analysis in this study.

Hop performance was measured with 3 single-leg hops: vertical hop (Muscle lab, Ergotest Technology, Oslo, Norway), hop for distance and a 30-second side-hop test. Each hop test was performed with the patients holding their hands behind their back. The hop tests have good validity and reliability for measuring hop performance in patients with an ACL injury or reconstruction.[14]

The results of the tests are presented as the Limb Symmetry Index (LSI), which is the result for the injured leg, divided by the result for the uninjured leg, multiplied by 100 and expressed as a percentage.

\section{Psychological patient-reported outcome}

The KOOS is valid and reliable for patients with an ACL injury.[16] The KOOS comprises 5 subscales: Pain, Symptoms, Activity of daily living, Function in sports and recreation, and QoL. Each item is rated from 0 to 4 on a 5-point Likert scale. In this study, the subscale of QoL was used.

The ACL-RSI has been developed to measure an athlete's psychological readiness to return to sport. The ACL-RSI is reliable, valid, and widely used to predict return to sport.[17, 18] Each item is graded from 0 to 10 , where 10 indicates the greatest readiness to return to sport. In this study, the 12 -item version was used.[18]

The Tegner Activity Scale (Tegner) is meant to reflect how strenuous a physical activity is for the knee.[19] The scale ranges from 0 to 10 , where 10 indicates the most knee strenuous physical activity. The scale has good validity for patients with an ACL reconstruction.[20] In the present study, a modified version was used.[12] The modified version does not contain any "0" value, which represents "sick leave or disability pension because of knee problems" in the original version of the Tegner, and has recreation sports as a choice up to level 9.

\section{Test batteries}

In this study, 4 different test batteries were evaluated. The names of the test batteries subsequently used in this paper are presented in Table 2: 


\section{Table 2. Test batteries used in the present study.}

\begin{tabular}{|c|c|c|c|}
\hline Type of test & Strength tests & Hop tests & PROs \\
\hline $2 \mathrm{MF}$ tests & & $\begin{array}{l}\text { - vertical hop } \\
\text { - hop for distance }\end{array}$ & \\
\hline $2 \mathrm{MF}$ tests $+2 \mathrm{PROs}$ & & $\begin{array}{l}\text { - vertical hop } \\
\text { - hop for distance }\end{array}$ & $\begin{array}{l}\text { - KOOS QoL } \\
\text { - ACL-RSI }\end{array}$ \\
\hline $5 \mathrm{MF}$ tests & $\begin{array}{l}\text { - knee extension } \\
\text { - knee flexion }\end{array}$ & $\begin{array}{l}\text { - vertical hop } \\
\text { - hop for distance } \\
\text { - side hop }\end{array}$ & \\
\hline $5 \mathrm{MF}$ tests + 2 PROs & $\begin{array}{l}\cdot \text { knee extension } \\
\cdot \text { knee flexion }\end{array}$ & $\begin{array}{l}\text { - vertical hop } \\
\text { - hop for distance } \\
\text { - side hop }\end{array}$ & $\begin{array}{l}\text { - KOOS QoL } \\
\text { - ACL-RSI }\end{array}$ \\
\hline
\end{tabular}

\section{Definition of passing}

Passing the tests of MF was defined as achieving an LSI value of $\geq 90 \%$.[5] When 2 or 5 tests of MF were taken into account, passing was achieved when the LSI was $\geq 90 \%$ in all tests taken into account.

For the psychological PROs, Muller et al.[21] suggested a score of 62.5 points for the KOOS QoL as a threshold for the state of "feeling well". With regard to the ACL-RSI, McPherson et al.[22] presented that a cut-off of 76.6 in young patients had maximal sensitivity $(78 \%$, with $39 \%$ specificity) for discriminating between patients who sustain a second ACL injury and patients who do not within 2 years from the index ACL reconstruction.[23] These 2 cut-offs were applied in this study and scores above the cut-offs were considered as passing.

\section{Statistics}

Statistical analysis was performed with the Statistical Package for Social Sciences (SPSS) (version 24, SPSS Inc., Chicago, IL, USA). Mean values, standard deviations, counts and percentages were calculated and presented for demographic data. To compare passing rates between the different test batteries, the sign test was used. Alpha was set at $<0.05$. To test correlations, the Phi coefficient was used for binary variables. Reference values used for the Phi coefficient was: $>0.05=$ weak; $>0.10=$ moderate; $>0.15=$ strong; >0.25 = very strong.[24]

\section{Results}

A total of 320 patients ( $51 \%$ men) met the final inclusion criteria for the study (Fig. 1). 
On average, patients were $27.1 \pm 9.4$ years old and had a BMl of $23.7 \pm 2.0 \mathrm{~kg} / \mathrm{m}^{2}$ at the time of ACL reconstruction. The majority of patients underwent $A C L$ reconstruction with a hamstring tendon autograft (85\%) (Table 3).

\section{Table 3. Demographic data. Mean values, standard deviations (SD), count (n) and proportions (\%) (n).}

\begin{tabular}{|c|c|c|c|}
\hline & $\begin{array}{l}\text { All subjects }(n= \\
320)\end{array}$ & Men $(n=164)$ & Women $(n=156)$ \\
\hline Age at reconstruction (years) & $27.1(9.4)$ & $27.5(8.9)$ & $26.6(9.9)$ \\
\hline Height (cm) & $175(9)$ & $181(7)$ & $167(6)$ \\
\hline Weight (kg) & $73(12)$ & $81(10)$ & $64(8)$ \\
\hline BMI & $24(2)$ & $24(2)$ & $23(2)$ \\
\hline $\begin{array}{l}\text { Days between injury and } \\
\text { reconstruction }\end{array}$ & $401(881)$ & $439(888)$ & $363(875)$ \\
\hline Hamstring graft, $\mathrm{n}(\%)$ & $272(85 \%)$ & $139(85 \%)$ & $133(85 \%)$ \\
\hline Patellar graft, n (\%) & $41(13 \%)$ & $22(13 \%)$ & $19(12.2 \%)$ \\
\hline Other graft, n (\%) & $6(2 \%)$ & $2(1 \%)$ & $4(2 \%)$ \\
\hline Preinjury Tegner: levels, n (\%) & $\begin{array}{l}1-5: 55(17 \%) \\
\text { 6-8: } 151(47 \%) \\
9-10: 114(36 \%)\end{array}$ & $\begin{array}{l}1-5: 23(14 \%) \\
\text { 6-8: } 71(43 \%) \\
9-10: 70(43 \%)\end{array}$ & $\begin{array}{l}1-5: 32(20 \%) \\
\text { 6-8: } 80(51 \%) \\
9-10: 44(28 \%)\end{array}$ \\
\hline 1-year Tegner: levels, n (\%) & $\begin{array}{l}\text { 1-5: } 123(38.5 \%) \\
\text { 6-8: } 127(39.8 \%) \\
\text { 9-10: } 45(14.1 \%) \\
\text { Missing: } 25(7.8 \%)\end{array}$ & $\begin{array}{l}\text { 1-5: } 67(40.8 \%) \\
\text { 6-8: } 55(33.6 \%) \\
\text { 9-10: } 30(18.2 \%) \\
\text { Missing: } 12 \\
(7.3 \%)\end{array}$ & $\begin{array}{l}\text { 1-5: } 56(35.9 \%) \\
\text { 6-8: } 72(46.2 \%) \\
9-10: 15(9.6 \%) \\
\text { Missing: } 13 \\
(8.3 \%)\end{array}$ \\
\hline
\end{tabular}

There were $47 \%(n=152)$ of the patients passing 2 MF tests (LSI $\geq 90 \%)$, compared with $19 \%(n=61)$ passing 2 MF tests +2 PROs ( $p \leq 0.001)$. There were $29 \%(n=92)$ passing 5 MF tests, compared with $13 \%(n=41)$ passing 5 MF tests +2 PROs ( $\leq 0.001)$ (Fig. 2). Passing rates (19\%) on 2 MF tests +2 PROs were significantly $(p \leq 0.001)$ lower than passing rates $(29 \%)$ on 5 MF tests.

A total of $47 \%(n=152)$ of the patients met the cut-off for ACL-RSI, while $62 \%(n=198)$ met the cut-off for KOOS QoL ( $p \leq 0.001)$. When adding ACL-RSI or KOOS QoL to $2 \mathrm{MF}$ tests, the passing rates decreased from $47 \%(n=152)$ to $20 \%(n=65)(A C L-R S I)$ and $31 \%(n=98)$ (KOOS QoL), respectively $(p \leq 0.001)$. When adding ACL-RSI or KOOS QoL to $5 \mathrm{MF}$ tests, the passing rates decreased from $29 \%(n=92)$ to $14 \%$ $(n=44)(A C L-R S I)$ and 20\% ( $n=63)(K O O S$ QoL), respectively ( $p \leq 0.001)$ (Fig. 3).

$\bigotimes=p<0.001$ in comparison between passing rates when adding each of the PROs; $2 \mathrm{MF}=$ vertical hop and hop for distance; $5 \mathrm{MF}$ tests = knee extension, knee flexion, vertical hop, hop for distance and side hop; 
ACL-RSI = The Anterior Cruciate Ligament Return to Sport after Injury; KOOS QoL = The Knee injury and Osteoarthritis Outcome Score, subscale Quality of Life; MF = muscle function; PRO = Patient Reported Outcome.

There was no significant correlation between passing cut-offs in both PROs and passing $2 \mathrm{MF}$ tests or 5 MF tests, respectively. Passing 2 MF tests +2 PROs resulted in a very strong correlation with passing 5 MF tests $\left(r_{\varphi}=0.412, p \leq 0.001\right)$ as well as passing 5 MF tests +2 PROs $\left(r_{\varphi}=0.790, p \leq 0.001\right)$.

\begin{tabular}{|lll}
\hline \multicolumn{2}{|l}{ Table 4. Correlation between different return to sport test batteries. } \\
\hline & Pass both PROs & P values \\
\hline Pass 2 MF tests & $r_{\varphi}=-0.22$ & 0.699 \\
\hline Pass 5 MF tests & $r_{\varphi}=0.43$ & 0.444 \\
\hline & Pass 2 MF tests + 2 PROs & \\
\hline Pass 5 MF tests & $r_{\varphi}=0.41$ & $\leq 0.001$ \\
\hline Pass 5 MF tests + 2 PROs & $r_{\varphi}=0.79$ & $\leq 0.001$ \\
\hline $\begin{array}{l}\text { PROs, patient-reported outcomes. } \\
r_{\varphi}=\text { Phi coefficient: }>0.05=\text { weak; }>0.10=\text { moderate; }>0.15=\text { strong; }>0.25=\text { very strong. }\end{array}$
\end{tabular}

\section{Discussion}

The main finding in this study was that using an RTS test battery comprising 2 hop tests and 2 PROs reduced the passing rate, and, thus, was more demanding, compared with using a battery of 5 MF tests (19\% versus $29 \%)$. Interestingly, there was a very strong correlation[24] between the two different test batteries. Therefore, a clinic without advanced testing equipment to measure strength can use 2 hop tests and 2 psychological PROs as criteria for RTS. The results are comparable or even better than a comprehensive battery of $5 \mathrm{MF}$ tests (strength and hop). There was no significant correlation between passing MF test batteries and reaching cut-offs for either KOOS QoL or ACL-RSI, which indicates that the use of only MF tests or only psychological outcomes is likely insufficient as RTS criteria.

Our results suggest that 1 in every 2 patients passed the RTS criteria and achieved symmetrical knee function, when the decision was based on reaching leg symmetry in 2 unilateral hop tests. With test batteries that comprise more tests, the passing rates decreased, in agreement with the literature.[8-10] More tests, thus, increase the demands on the patients recovery after ACL reconstruction. When $5 \mathrm{MF}$ tests with or without 2 PROs were used, the passing rate, compared with only 2 hop tests, decreased from $47 \%$ to approximately $29 \%$ and $13 \%$, respectively. The use of only 2 hop tests to determine symmetrical muscle function can, therefore, not be recommended, as approximately $30 \%$ of patients run the risk of being classified as false positives. 
Current recommendations for RTS evaluation, ${ }^{25}$ are strongly supported by results from the present study, suggesting that batteries of tests should comprise strength and hop tests, as well as PROs.[25, 26] In our cohort, a very small proportion of patients met our recommended RTS criteria at 1 year after ACL reconstruction. This result indicates that clinical settings, included in Project ACL, and responsible medical professionals for the treatment of the patients in this study, need to better prepare patients in order to make a safe RTS.

The results of low psychological readiness to RTS and unacceptable low knee-related QoL suggest that some patients have recovered MF without recovering the psychological outcome. Psychological factors are important during rehabilitation,[27, 28] where for example, high fear of re-injury can prevent patients from returning to their preinjury level of sport.[29-31] Furthermore, a lower psychological readiness to RTS 1 year after ACL reconstruction is associated with a higher risk of a second ACL injury,[23] supporting that it is important to include psychological PROs in RTS decision-making, alongside tests of MF.

In this study, a smaller proportion of patients met the criteria for an acceptable ACL-RSI compared with KOOS QoL. The ACL-RSI was developed to assess psychological readiness to RTS.[17] However, the impact RTS has on ACL-RSI, i.e. whether RTS leads to high psychological readiness or whether high psychological readiness leads to RTS, is yet to be studied. Patients who do not RTS after ACL reconstruction can report poor knee-related QoL up to 20 years after surgery, compared with patients who RTS.[32] However, the use of both the KOOS QoL and the ACL-RSI led to more patients being identified as not "recovered" compared with using only MF tests. Future studies are needed to better understand how individual psychological profiles are related to a safe RTS.

Given the high rate of new knee-related injuries in patients after ACL reconstruction $[33,34]$ and the assumption that patients who RTS might not have been ready for it, more emphasis should be placed on preparing patients for RTS test battery criteria during rehabilitation, especially as passing RTS test batteries can reduce the risk of re-injury.[4]

\section{Limitations and strengths}

A limitation of this study is that we did not determine the different test batteries effectiveness to reduce the risk of a second ACL injury. Even though there is evidence[4,35] suggesting that patients who meet certain cut-offs in RTS test batteries have lower risk for a second ACL injury, there is an ongoing debate [36],[37] about the evidence and the validity of RTS testing.

The use of the LSI is a limitation since the patients' healthy limb can have reduced strength after ACL reconstruction,[38] meaning that tests of muscle function may overestimate the function of the operated limb.[39] Results in the present study might therefore be falsely high, which strengthens the recommendation that RTS criteria are important to meet before RTS.

Patients who suffered a second ACL rupture were excluded from the present study in order to create a group of patients that was as homogeneous as possible. Future studies will show how the different 
batteries of tests assessed in this study affect the risk of a new ACL injury.

The primary strength of this study is the relatively large number of patients included. Another strength is the choice of PROs, since the KOOS and the ACL-RSI was used, and these PROs have high methodological quality.[40]

\section{Conclusion}

The use of hop tests together with psychological PROs provides a demanding and clinician-friendly RTS test battery one year after $\mathrm{ACL}$ reconstruction.

\section{List Of Abbreviations}

RTS, Return to Sport

$\mathrm{ACL}$, Anterior Cruciate Ligament

MF, Muscle Function

PROs, Patient Reported Outcomes

KOOS QoL, Knee injury and Osteoarthritis Outcome Score, subscale Quality of Life

ACL-RSI, ACL Return to Sport after Injury scale

LSI, Limb Symmetry Index

SPSS, Statistical Package for Social Sciences

\section{Declarations}

Ethics approval and consent to participate: Ethical approval was obtained from the Regional Ethical Review Board in Gothenburg, Sweden (registration numbers: 265-13, T023-17).

Consent for publication: Not applicable

Availability of data and materials: The dataset used and/or analyzed during the current study are available from the corresponding author on reasonable request.

Competing interests: The authors declare have no competing interests to declare.

Funding: No funding was received.

Authors 'contributions: Authors RT, EHS and SB have contributed to the design of Project ACL and all the included methods and follow-ups that have made this specific study possible. 
Authors RP and EHS are responsible for drafting the manuscript and have contributed substantially to the research question and the analysis of data.

Authors RP, EHS, SB and RT have made major contributions by critically revising the manuscript for important intellectual content.

Acknowledgments: The authors acknowledge Christoffer Thomeé for technical support of the Project ACL database.

\section{References}

1. Ardern CL, Taylor NF, Feller JA, Whitehead TS, Webster KE. Sports participation 2 years after anterior cruciate ligament reconstruction in athletes who had not returned to sport at 1 year: a prospective follow-up of physical function and psychological factors in 122 athletes. Am J Sports Med. 2015;43(4):848-56.

2. Ardern CL, Webster KE, Taylor NF, Feller JA. Return to sport following anterior cruciate ligament reconstruction surgery: a systematic review and meta-analysis of the state of play. Br J Sports Med. 2011;45(7):596-606.

3. Svantesson E, Hamrin Senorski E, Baldari A, Ayeni OR, Engebretsen L, Franceschi F, et al. Factors associated with additional anterior cruciate ligament reconstruction and register comparison: a systematic review on the Scandinavian knee ligament registers. Br J Sports Med. 2019;53(7):418-25.

4. Grindem H, Snyder-Mackler L, Moksnes H, Engebretsen L, Risberg MA. Simple decision rules can reduce reinjury risk by $84 \%$ after $A C L$ reconstruction: the Delaware-Oslo ACL cohort study. $\mathrm{Br} \mathrm{J}$ Sports Med. 2016;50(13):804-8.

5. Lynch AD, Logerstedt DS, Grindem H, Eitzen I, Hicks GE, Axe MJ, et al. Consensus criteria for defining 'successful outcome' after ACL injury and reconstruction: a Delaware-Oslo ACL cohort investigation. Br J Sports Med. 2015;49(5):335-42.

6. Weiss MR. Psychological Aspects of Sport-Injury Rehabilitation: A Developmental Perspective. J Athl Train. 2003;38(2):172-5.

7. Wiese-Bjornstal DM, Smith AM, Shaffer SM, Morrey MAJJoasp. An integrated model of response to sport injury: Psychological and sociological dynamics. 1998;10(1):46-69.

8. Herrington L, Ghulam H, Comfort P. Quadriceps Strength and Functional Performance After Anterior Cruciate Ligament Reconstruction in Professional Soccer players at Time of Return to Sport. J Strength Cond Res. 2018.

9. Thomee R, Neeter C, Gustavsson A, Thomee P, Augustsson J, Eriksson B, et al. Variability in leg muscle power and hop performance after anterior cruciate ligament reconstruction. Knee Surg Sports Traumatol Arthrosc. 2012;20(6):1143-51.

10. Welling W, Benjaminse A, Seil R, Lemmink K, Zaffagnini S, Gokeler A. Low rates of patients meeting return to sport criteria 9 months after anterior cruciate ligament reconstruction: a prospective 
longitudinal study. Knee Surg Sports Traumatol Arthrosc. 2018;26(12):3636-44.

11. Beischer S, Hamrin Senorski E, Thomee C, Samuelsson K, Thomee R. How Is Psychological Outcome Related to Knee Function and Return to Sport Among Adolescent Athletes After Anterior Cruciate Ligament Reconstruction? Am J Sports Med. 2019;47(7):1567-75.

12. Hamrin Senorski E, Samuelsson K, Thomee C, Beischer S, Karlsson J, Thomee R. Return to kneestrenuous sport after anterior cruciate ligament reconstruction: a report from a rehabilitation outcome registry of patient characteristics. Knee Surg Sports Traumatol Arthrosc. 2017;25(5):136474.

13. Beischer S, Hamrin Senorski E, Thomee C, Samuelsson K, Thomee R. Knee strength, hop performance and self-efficacy at 4 months are associated with symmetrical knee muscle function in young athletes 1 year after an anterior cruciate ligament reconstruction. BMJ Open Sport Exerc Med. 2019;5(1):e000504.

14. Gustavsson A, Neeter C, Thomee P, Silbernagel KG, Augustsson J, Thomee R, et al. A test battery for evaluating hop performance in patients with an $A C L$ injury and patients who have undergone ACL reconstruction. Knee Surg Sports Traumatol Arthrosc. 2006;14(8):778-88.

15. Feiring DC, Ellenbecker TS, Derscheid GL. Test-Retest Reliability of the Biodex Isokinetic Dynamometer. Journal of Orthopaedic \& Sports Physical Therapy. 1990;11(7):298-300.

16. Roos EM, Lohmander LS. The Knee injury and Osteoarthritis Outcome Score (KOOS): from joint injury to osteoarthritis. Health Qual Life Outcomes. 2003;1:64.

17. Webster KE, Feller JA, Lambros C. Development and preliminary validation of a scale to measure the psychological impact of returning to sport following anterior cruciate ligament reconstruction surgery. Phys Ther Sport. 2008;9(1):9-15.

18. Webster KE, Feller JA. Development and Validation of a Short Version of the Anterior Cruciate Ligament Return to Sport After Injury (ACL-RSI) Scale. Orthop J Sports Med. 2018;6(4):2325967118763763.

19. Tegner Y, Lysholm J. Rating systems in the evaluation of knee ligament injuries. Clin Orthop Relat Res. 1985(198):43-9.

20. Kong DH, Yang SJ, Ha JK, Jang SH, Seo JG, Kim JG. Validation of functional performance tests after anterior cruciate ligament reconstruction. Knee Surg Relat Res. 2012;24(1):40-5.

21. Muller B, Yabroudi MA, Lynch A, Lai CL, van Dijk CN, Fu FH, et al. Defining Thresholds for the Patient Acceptable Symptom State for the IKDC Subjective Knee Form and KOOS for Patients Who Underwent ACL Reconstruction. Am J Sports Med. 2016;44(11):2820-6.

22. Ardern CL, Taylor NF, Feller JA, Whitehead TS, Webster KE. Psychological responses matter in returning to preinjury level of sport after anterior cruciate ligament reconstruction surgery. Am J Sports Med. 2013;41(7):1549-58.

23. McPherson AL, Feller JA, Hewett TE, Webster KE. Psychological Readiness to Return to Sport Is Associated With Second Anterior Cruciate Ligament Injuries. Am J Sports Med. 2019;47(4):857-62.

24. Akoglu H. User's guide to correlation coefficients. Turk J Emerg Med. 2018;18(3):91-3. 
25. Lynch AD, Logerstedt DS, Grindem H, Eitzen I, Hicks GE, Axe MJ, et al. Consensus criteria for defining 'successful outcome' after ACL injury and reconstruction: a Delaware-Oslo ACL cohort investigation. Br J Sports Med. 2015;49(5):335-42.

26. Thomee R, Kaplan Y, Kvist J, Myklebust G, Risberg MA, Theisen D, et al. Muscle strength and hop performance criteria prior to return to sports after ACL reconstruction. Knee Surg Sports Traumatol Arthrosc. 2011;19(11):1798-805.

27. Sonesson S, Kvist J, Ardern C, Osterberg A, Silbernagel KG. Psychological factors are important to return to pre-injury sport activity after anterior cruciate ligament reconstruction: expect and motivate to satisfy. Knee Surg Sports Traumatol Arthrosc. 2017;25(5):1375-84.

28. Webster KE, Feller JA. A research update on the state of play for return to sport after anterior cruciate ligament reconstruction. J Orthop Traumatol. 2019;20(1):10.

29. Kvist J, Ek A, Sporrstedt K, Good L. Fear of re-injury: a hindrance for returning to sports after anterior cruciate ligament reconstruction. Knee Surg Sports Traumatol Arthrosc. 2005;13(5):393-7.

30. McVeigh F, Pack SM. An exploration of sports rehabilitators' and athletic rehabilitation therapists' views on fear of reinjury after anterior cruciate ligament reconstruction. J Sport Rehabil. 2015;24(2):140-50.

31. DiSanti J, Lisee C, Erickson K, Bell D, Shingles M, Kuenze C. Perceptions of Rehabilitation and Return to Sport Among High School Athletes With Anterior Cruciate Ligament Reconstruction: A Qualitative Research Study. J Orthop Sports Phys Ther. 2018;48(12):951-9.

32. Filbay SR. Longer-term quality of life following ACL injury and reconstruction. Br J Sports Med. 2018;52(3):208-9.

33. Webster KE, Feller JA, Leigh WB, Richmond AK. Younger patients are at increased risk for graft rupture and contralateral injury after anterior cruciate ligament reconstruction. Am J Sports Med. 2014;42(3):641-7.

34. Snaebjörnsson T, Hamrin Senorski E, Sundemo D, Svantesson E, Westin O, Musahl V, et al. Adolescents and female patients are at increased risk for contralateral anterior cruciate ligament reconstruction: a cohort study from the Swedish National Knee Ligament Register based on 17,682 patients. Knee Surg Sports Traumatol Arthrosc. 2017;25(12):3938-44.

35. Kyritsis P, Bahr R, Landreau P, Miladi R, Witvrouw E. Likelihood of ACL graft rupture: not meeting six clinical discharge criteria before return to sport is associated with a four times greater risk of rupture. British journal of sports medicine. 2016;50(15):946-51.

36. Webster KE, Hewett TE. What is the Evidence for and Validity of Return-to-Sport Testing after Anterior Cruciate Ligament Reconstruction Surgery? A Systematic Review and Meta-Analysis. Sports Med. 2019;49(6):917-29.

37. Capin JJ, Snyder-Mackler L, Risberg MA, Grindem H. Keep calm and carry on testing: a substantive reanalysis and critique of 'what is the evidence for and validity of return-to-sport testing after anterior cruciate ligament reconstruction surgery? A systematic review and meta-analysis'. British journal of sports medicine. 2019;53(23):1444-6. 
38. Hiemstra L, Webber S, Macdonald P, Kriellaars D. Contralateral limb strength deficits after anterior cruciate ligament reconstruction using a hamstring tendon graft. Clinical biomechanics (Bristol, Avon). 2007;22:543-50.

39. Wellsandt E, Failla MJ, Snyder-Mackler L. Limb Symmetry Indexes Can Overestimate Knee Function After Anterior Cruciate Ligament Injury. J Orthop Sports Phys Ther. 2017;47(5):334-8.

40. Gagnier JJ, Shen Y, Huang H. Psychometric Properties of Patient-Reported Outcome Measures for Use in Patients with Anterior Cruciate Ligament Injuries: A Systematic Review. JBJS Rev. 2018;6(4):e5.

\section{Figures}


Patients registered in Project ACL up to February 2019 with one ACL injury

$\mathrm{n}=1872$

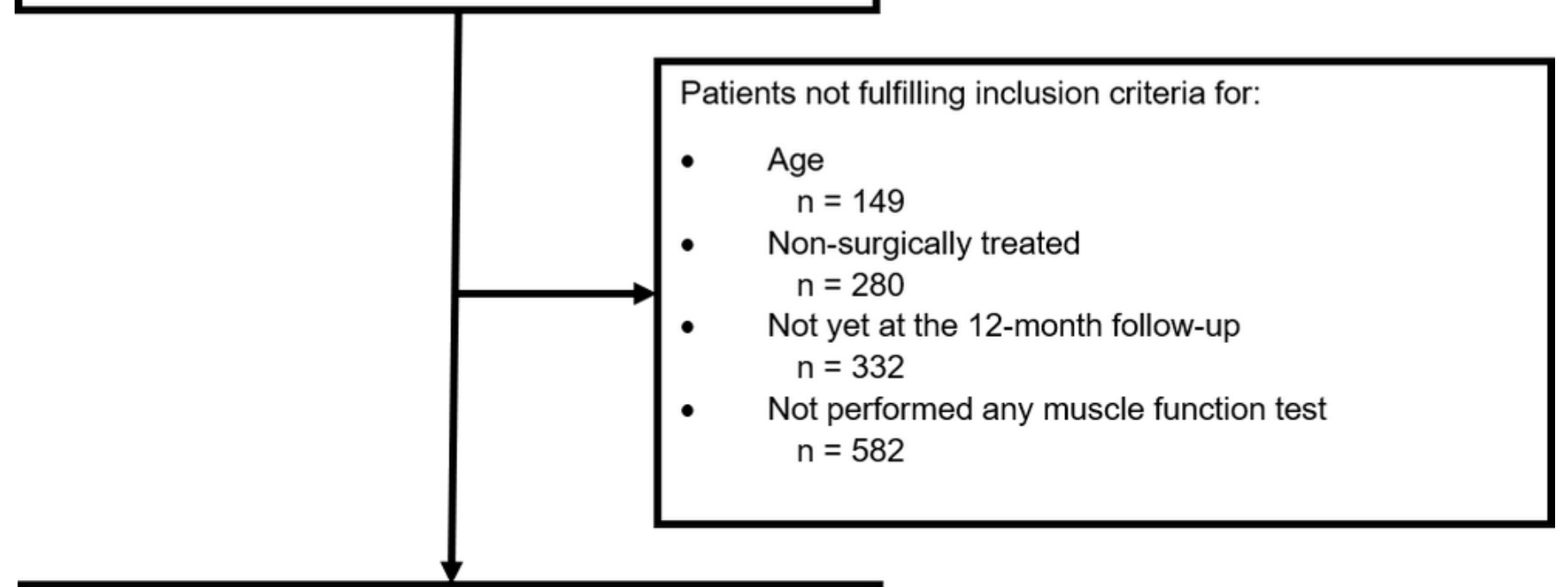

Patients eligible for inclusion in the present study

$$
n=531
$$

Patients excluded due to

- $\quad$ Not performing all muscle function tests

$$
\mathrm{n}=150
$$

- $\quad$ Not completing either KOOS QoL or ACL-RSI

$$
\mathrm{n}=59
$$

Patients included in the present study

$$
\mathrm{n}=320
$$

\section{Figure 1}

Flowchart of included and excluded patients. $\mathrm{n}=$ number. 
$50 \%$

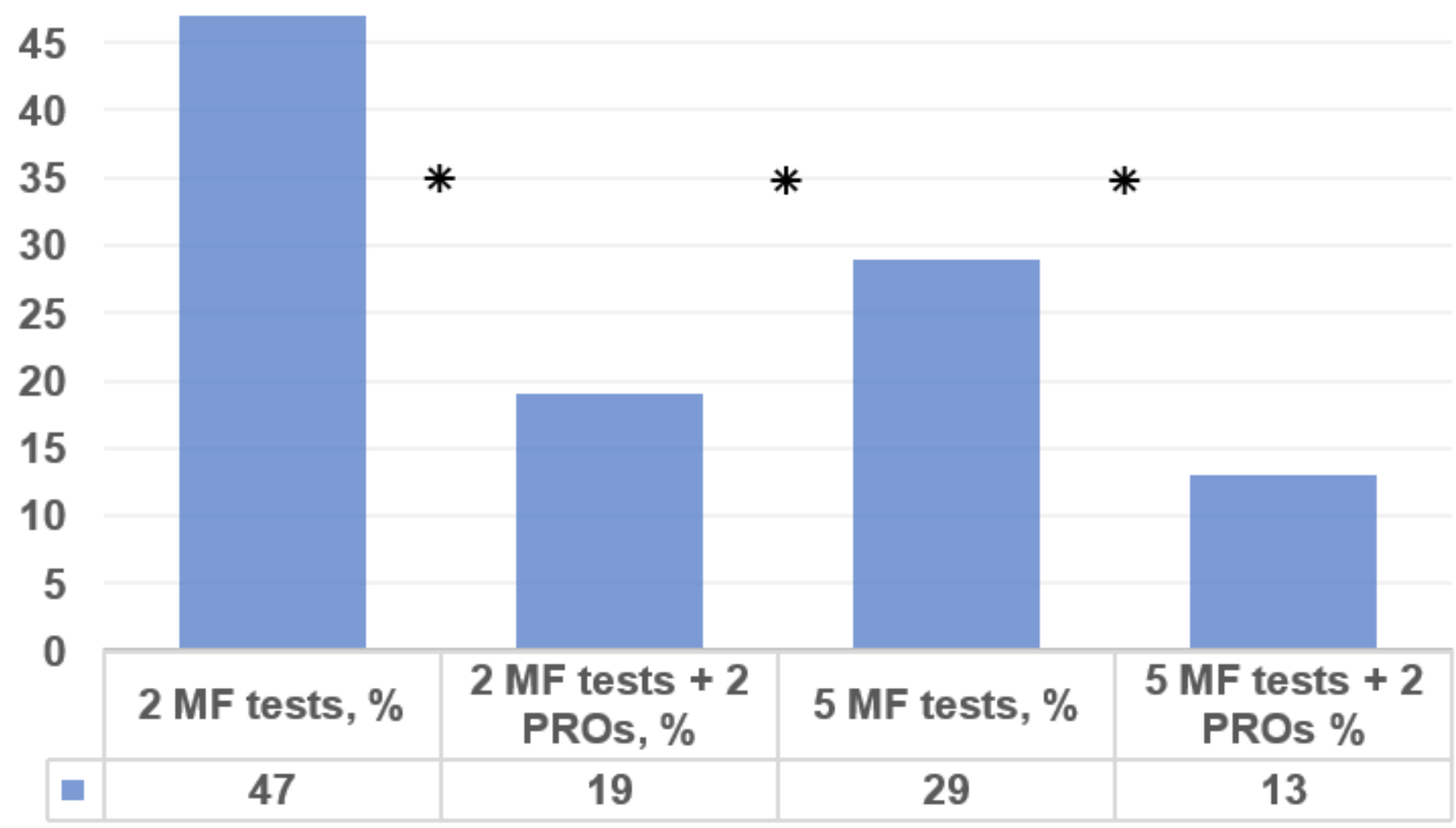

Figure 2

Proportion (\%) of 320 patients passing the different return to sport test batteries; $2 \mathrm{MF}=$ vertical hop and hop for distance; $2 \mathrm{MF}+2 \mathrm{PROs}$ = vertical hop, hop for distance, KOOS QoL and ACL-RSI; $5 \mathrm{MF}$ tests = knee extension, knee flexion, vertical hop, hop for distance and side hop; $5 \mathrm{MF}$ tests +2 PROs $=$ knee extension, knee flexion, vertical hop, hop for distance, side hop, KOOS QoL and ACL-RSI; $\triangle=p<0.001$; ACL$\mathrm{RSI}=$ The Anterior Cruciate Ligament Return to Sport after Injury; KOOS QoL = The Knee injury and Osteoarthritis Outcome Score, subscale Quality of Life; MF = muscle function; PRO = Patient Reported Outcome. 


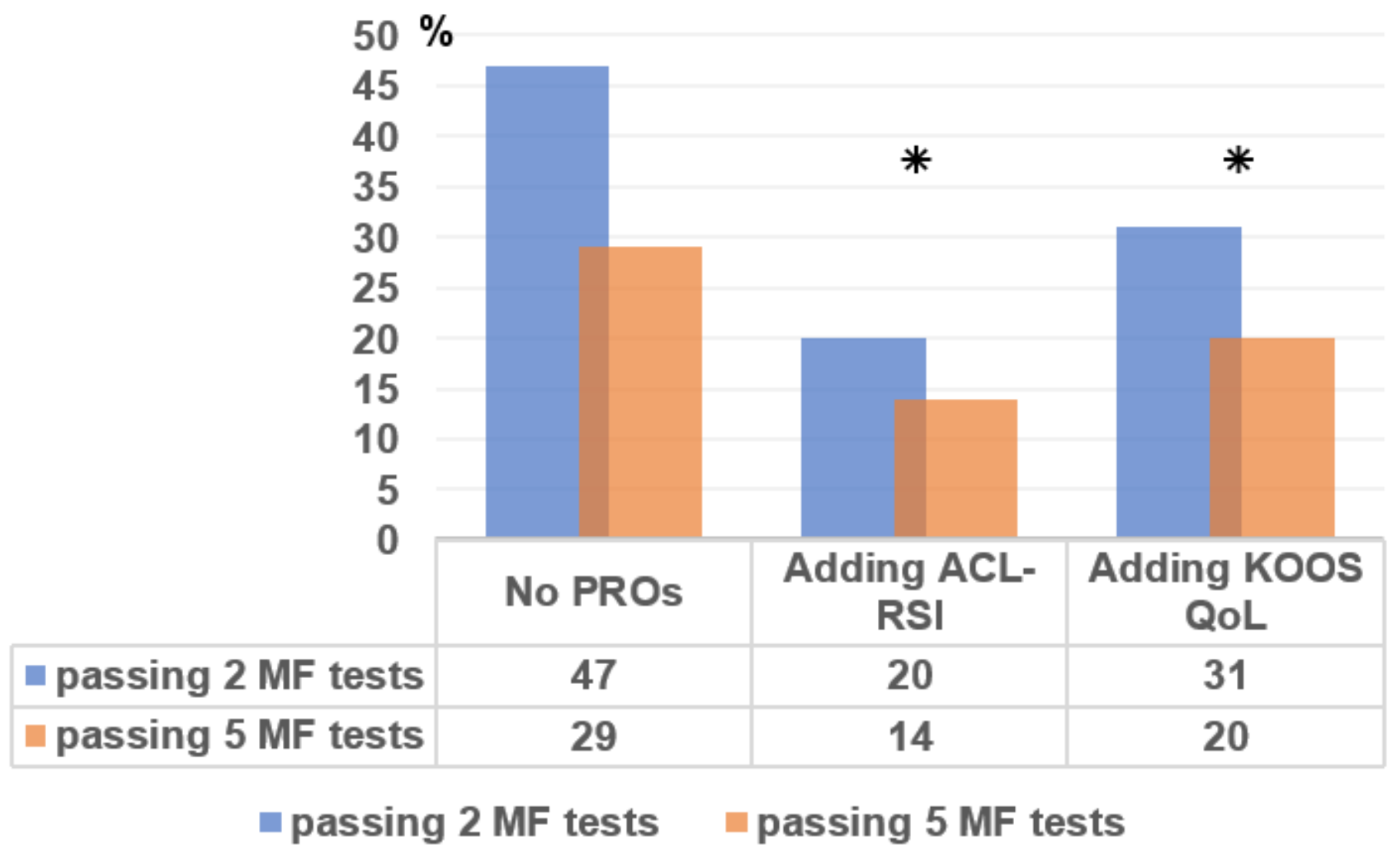

Figure 3

Proportion of patients passing cut-offs when adding one PRO at a time. $\nabla=p<0.001$ in comparison between passing rates when adding each of the PROs; $2 \mathrm{MF}=$ vertical hop and hop for distance; $5 \mathrm{MF}$ tests $=$ knee extension, knee flexion, vertical hop, hop for distance and side hop; ACL-RSI = The Anterior Cruciate Ligament Return to Sport after Injury; KOOS QoL = The Knee injury and Osteoarthritis Outcome Score, subscale Quality of Life; MF = muscle function; PRO = Patient Reported Outcome. 